\title{
Comparison of Canine-Guided Occlusion with Other Occlusal Schemes in Removable Complete Dentures: A Systematic Review
}

\author{
Naseer Ahmed ${ }^{1,2}$, Muhammad Anas Humayun ${ }^{2}$, Maria Shakoor Abbasi ${ }^{2}\left(\mathbb{D}\right.$, Nafij Bin Jamayet $^{3}(\mathbb{D}$, \\ Syed Rashid Habib ${ }^{(D)}$ and Muhammad Sohail Zafar $5,6, *$ (D)
}

1 Department of Prosthodontics, School of Dental Sciences, Universiti Sains Malaysia Health Campus, Kubang Kerian, Kota Bharu 16150, Malaysia; naseerahmed@student.usm.my

2 Department of Prosthodontics, Altamash Institute of Dental Medicine, Karachi 75500, Pakistan; dr.anashumayun333@gmail.com (M.A.H.); maria_shakoor@hotmail.com (M.S.A.)

3 Division of Clinical Dentistry, Prosthodontics, School of Dentistry, International Medical University, Jalan Jalil Perkasa 19, Bukit Jalil, Kuala Lumpur 5700, Malaysia; dr.nafij@gmail.com

4 Department of Prosthetic Dental Sciences, College of Dentistry, King Saud University, Riyadh 11545, Saudi Arabia; syhabib@ksu.edu.sa

5 Department of Restorative Dentistry, College of Dentistry, Taibah University, Al Madinah, Al Munawwarah 41311, Saudi Arabia

6 Department of Dental Materials, Islamic International Dental College, Riphah International University, Islamabad 44000, Pakistan

* Correspondence: MZAFAR@taibahu.edu.sa; Tel.: +966-50-754-4691

Citation: Ahmed, N.;

Humayun, M.A.; Abbasi, M.S.; Jamayet, N.B.; Habib, S.R.; Zafar, M.S. Comparison of Canine-Guided Occlusion with Other Occlusal Schemes in Removable Complete Dentures: A Systematic Review. Prosthesis 2021, 3, 85-98. https:// doi.org/10.3390/prosthesis3010009

Received: 16 February 2021

Accepted: 9 March 2021

Published: 11 March 2021

Publisher's Note: MDPI stays neutral with regard to jurisdictional claims in published maps and institutional affiliations.

Copyright: (c) 2021 by the authors. Licensee MDPI, Basel, Switzerland. This article is an open access article distributed under the terms and conditions of the Creative Commons Attribution (CC BY) license (https:// creativecommons.org/licenses/by/ $4.0 /)$.
Abstract: Choosing an adequate occlusion is challenging during the construction of artificial dentures, and critical for patient satisfaction. However, there is no conclusive evidence to support which occlusal design is more appropriate. The aim of this systematic review was to evaluate canine-guided occlusion in comparison to other occlusal schemes in removable complete denture wearers. The review was conducted according to the Preferred Reported Items for Systematic Review and MetaAnalysis (PRISMA) guidelines. An extensive search was carried out on (PubMed (National Library of Medicine)), Scopus (Elsevier), Cochrane collaboration (Wiley), Science Direct (Elsevier) and Europe PMC (European Bioinformatics Institute). English and non-English studies were identified using keywords on canine-guided occlusion, denture occlusion, dental occlusion and artificial occlusal schemes. Out of 1759 articles searched, 18 were selected based on the inclusion criteria. The included studies were interpreted for the descriptive analysis for the calculation of occlusal schemes, occlusion assessment parameters, the outcome of the occlusal schemes and types of removable prosthesis used. The systematic analysis of occlusal schemes revealed that canine-guided occlusion is viable compared with other occlusal designs in terms of patient satisfaction, mastication, retention, esthetics, phonetics, oral-health-related quality of life and muscle activity. The type of occlusal scheme influences the complete denture patient's' masticatory efficiency, satisfaction, retention, phonetics and esthetics. Nevertheless, physical, physiological, mechanical and psychological factors play a vital role in the success of removable complete dentures. The canine-guided occlusal scheme is preferred because of its simplicity, less time consumption, good masticatory performance, ease of fabrication and modification into bilateral balanced occlusion if required. Further studies are required to reduce the controversies related to jaw relations, gnathology and occlusal schemes in complete dentures.

Keywords: prosthetic dentistry; denture occlusion; bilateral balanced occlusion; canine-guided occlusion; prosthodontics; complete denture

\section{Introduction}

Removable complete denture (CD) occlusal schemes have a varied perception in terms of satisfaction and oral-health-related quality of life in patients [1]. The three pillars for 
the success of removable dentures are retention, stability and support, which directly affect the function, phonetics and aesthetic of patients. The factors are equally associated with restorations in both arches but complicated in the mandibular arch. Problems are associated with artificial dentures of both conventional and implant-supported categories with continuous denture use [2]. However, the use of tissue-friendly techniques and materials can improve the patient satisfaction level and biocompatibility [3]. Occlusion is an integral component of complete denture biomechanics. Satisfactory occlusal scheme prescription is a supporting factor to a better removable complete denture outcome in patients. It is evident that adjusting the occlusion clinically and in laboratory increases patients' acceptance with time [4].

Numerous occlusal schemes for removable complete dentures are in practice, including bilateral balanced occlusion (BBO), lingualized occlusion (LO), buccal occlusion (BO), monoplane occlusion (MO), group function/ unilateral balanced (GF) and canine-guided occlusion (CGO). Occlusal schemes are diversified and continuously changing over time, hence today's restorative dentists are in a state of uncertainty as to which occlusal schemes can be satisfactorily incorporated in dentures [5]. Occlusal schemes are primarily selected on the basis of the amount of ridge resorption in the upper or lower dental arches and the state of the stomatognathic system. In addition, certain systemic conditions are associated with specific occlusal schemes. For example, $\mathrm{MO}$ is particularly used in muscle disorders [6], while $\mathrm{LO}$ is believed to serve better in resorbed ridges compared to BBO. $\mathrm{BO}$ is associated with improved chewing ability and patient preference for a variety of foods. BBO is associated with better stability, retention and support of removable complete dentures [7]. There are studies reporting the limitations of LO and BBO due to the lack of patient satisfaction particularly in removable dentures [8], which creates room for further investigation to rule out the possibility of other occlusal schemes. The use of removable complete dentures will not reduce in the future, hence researchers must focus on a reliable occlusal scheme that has maximum outcome in terms of quality patient service [9]. CGO is considered less problematic in terms of occlusal interferences, esthetics, occlusal surface contacts in denture teeth and satisfaction levels with simple occlusal adjustments [10]. In this review, we performed a comprehensive search of clinical trials emphasizing properties of the CGO scheme and comparing them with the characteristics of $\mathrm{LO}, \mathrm{BBO}$ and $\mathrm{MO}$ and question whether CGO is ideal for successful removable complete denture treatment or not. The analysis of oral-health-related quality of life (OHRQoL), muscle activity, aesthetics, chewing ability, retention and stability were considered as the treatment outcome.

\section{Materials and Methods}

\subsection{Research Question}

This systematic review was conducted according to the Preferred Reported Items for Systematic Review and Meta-Analysis (PRISMA) guidelines. The focused question of "Is canine-guided occlusion a reliable occlusal scheme for the arrangement of complete denture teeth when compared to relevant published artificial occlusal schemes?" was constructed utilizing the Participants Intervention Control and Outcomes (PICO) strategy [11].

\subsection{Search Strategy and Eligibility Criteria}

An electronic literature search was conducted using various databases (PubMed (National Library of Medicine)), Scopus (Elsevier), Cochrane collaboration (Wiley), Science Direct (Elsevier) and Europe PMC (European Bioinformatics Institute) using various combinations of keywords (canine-guided occlusion, denture occlusion, dental occlusion, balanced occlusion, lingualized occlusion, monoplane occlusion). Clinical trials published (on or before 31 May 2020) were included without any language and publication date restrictions. The following inclusion criteria were applied: human studies with at least five participants, focus on CGO, removable/implant-retained complete dentures, evaluation of participants' satisfaction level, OHRQoL, retention, stability, chewing ability, muscle activity and esthetics, as presented in (Figure 1). 

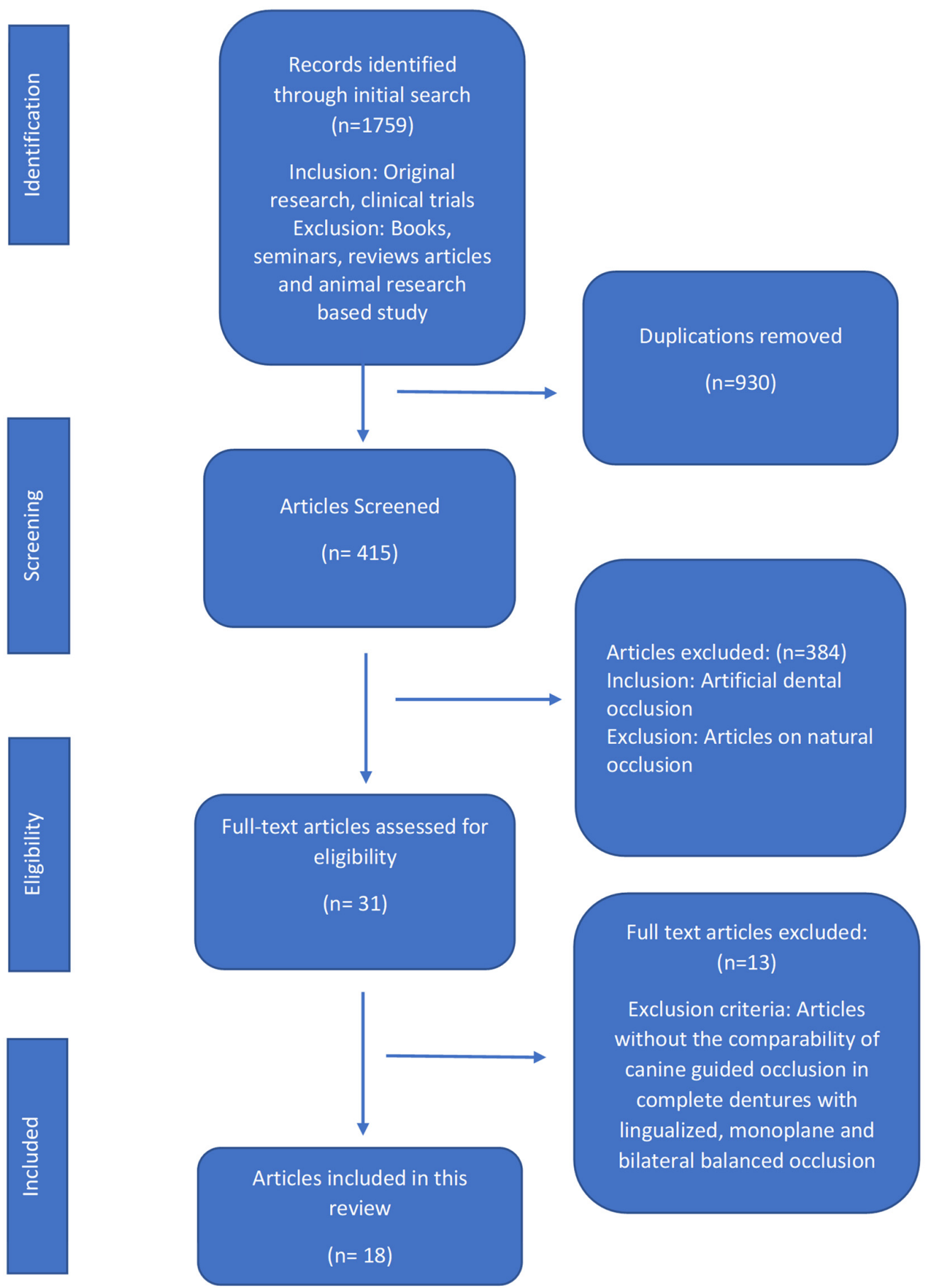

Figure 1. Flow diagram of selected articles and literature search as per the Preferred Reported Items for Systematic Review and Meta-Analysis (PRISMA) guidelines.

Two investigators (N.A. and M.S.Z.) screened the eligible articles against the inclusion criteria and performed a self-dependent eligibility appraisal.

The search was extended by including articles from the reference list to explore further relevant studies. Any disagreement was discussed and resolved by a consensus. The data were collected from every article according to the following specifications: author identification, study design, number of participants, type of prosthesis used, occlusal schemes opted, occlusal assessment method, i.e., patient satisfaction, function or mastication, phonetics, retention, esthetics, muscle activity and OHRQoL, follow-up period and outcome of the study, as described in (Table 1). The extracted data was entered in SPSS version 25 for statistical analysis. The descriptive analysis (frequency and percentage calculation) of 
occlusal schemes, occlusion assessment parameters, outcome of the occlusal schemes and types of removable prosthesis used in included studies were performed and interpreted.

\subsection{Quality Assessment of the Included Articles}

A quality assessment of the included articles was carried out according to the standards described in the Cochrane Handbook for Systematic Reviews of Interventions (version 5.1.0) [12] and on the basis of parameters, i.e., patient chosen randomly, blinding, withdrawal/dropout mentioned or not, statistics applied, sample size estimation, inclusion/exclusion criteria, measurement of occlusal performance and method of error assessment (Table 2). Both investigators screened the included clinical trials, and any confusion was solved by consultation with a third reviewer. The Newcastle-Ottawa quality assessment scale (NOS) for randomized controlled trials [13] was used for further analysis of the included articles (Table 3). 
Table 1. Characteristics of included studies.

\begin{tabular}{|c|c|c|c|c|c|c|}
\hline Study & Study Design and Participants & Prosthesis & Occlusion & Assessment Method & $\begin{array}{l}\text { Follow-Up } \\
\text { Period }\end{array}$ & Conclusions \\
\hline Pero et al. [9] & Crossover, 30 & Complete dentures & $\begin{array}{l}\text { CGO } \\
\text { BBO }\end{array}$ & $\begin{array}{l}\text { Occlusal force } \\
\text { Mastication }\end{array}$ & 4 weeks & $\mathrm{CGO}$ is a viable alternative to $\mathrm{BBO}$ in complete dentures \\
\hline Brandt et al. [10] & Crossover, 40 & Complete dentures & $\begin{array}{l}\text { CGO } \\
\text { BBO }\end{array}$ & $\begin{array}{l}\text { Esthetics, retention } \\
\text { Phonetics, mastication }\end{array}$ & 12 weeks & $\begin{array}{c}\text { CGO can be a comfortable alternative to } \mathrm{BBO} \text { in complete } \\
\text { dentures }\end{array}$ \\
\hline Schierz et al. [1] & $\begin{array}{l}\text { Randomized single-blind } \\
\text { crossover trial, } 19\end{array}$ & Complete dentures & $\begin{array}{l}\text { CGO } \\
\text { BBO }\end{array}$ & OHRQoL & 12 weeks & $\mathrm{CGO}$ and $\mathrm{BBO}$ are similar in terms of $\mathrm{OHRQoL}$ \\
\hline Peroz et al. [14] & Randomized control trial, 22 & Complete dentures & $\begin{array}{l}\text { CGO } \\
\text { BBO }\end{array}$ & $\begin{array}{l}\text { Esthetics, retention } \\
\text { Mastication, phonetic }\end{array}$ & 12 weeks & $\begin{array}{l}\text { CGO can be used successfully in complete denture } \\
\text { treatment. CGO showed better esthetics, chewing and } \\
\text { lower denture retention, while BBO had a limited role in the } \\
\text { studied parameters but showed better retention in the } \\
\text { upper denture }\end{array}$ \\
\hline Farias et al. [15] & $\begin{array}{l}\text { Double-blinded controlled } \\
\text { crossover clinical trial, } 24\end{array}$ & Complete denture & $\begin{array}{l}\text { CGO } \\
\mathrm{BBO}\end{array}$ & $\begin{array}{l}\text { Mastication, phonetics, } \\
\text { esthetics } \\
\text { Retention, patient satisfaction, } \\
\text { comfort }\end{array}$ & 12 weeks and 24 weeks & $\begin{array}{l}\text { CGO is preferred, easier and faster. } \mathrm{BBO} \text { does not improve } \\
\text { masticatory efficiency in complete denture wearers }\end{array}$ \\
\hline Abdelhamid et al. [16] & Crossover, 12 & $\begin{array}{l}\text { Implant-retained lower } \\
\text { overdenture } \\
\text { and an upper conventional } \\
\text { complete denture }\end{array}$ & $\begin{array}{l}\text { CGO } \\
\text { BBO }\end{array}$ & $\begin{array}{l}\text { Electromyography of the } \\
\text { masseter muscles } \\
\text { Mastication }\end{array}$ & 4 weeks & $\begin{array}{l}\text { Both CGO and BBO can be used successfully in } \\
\text { implant-retained mandibular denture as analyzed by } \\
\text { electromyography }\end{array}$ \\
\hline Heydecke et al. [7] & Randomized crossover, 20 & Complete denture & $\begin{array}{l}\text { CGO } \\
\text { LO }\end{array}$ & Mastication & 12 weeks & LO is not superior to CGO in chewing ability \\
\hline Bolla et al. [18] & Clinical trial, 20 & Complete dentures & $\begin{array}{l}\text { CGO } \\
\text { BBO }\end{array}$ & $\begin{array}{l}\text { Patient satisfaction } \\
\text { Mastication } \\
\text { Esthetics } \\
\text { Adaptability } \\
\text { Retention } \\
\text { Phonetics } \\
\end{array}$ & $12-16$ weeks and yearly & $\begin{array}{l}\text { BBO showed better initial adaptation in denture wearers. } \\
\text { CGO can be used with success. Occlusion adaptation is not } \\
\text { a crucial factor for patient adaptation }\end{array}$ \\
\hline Faten et al. [19] & Crossover clinical trial, 20 & Complete dentures & $\begin{array}{l}\text { CGO } \\
\text { BBO }\end{array}$ & $\begin{array}{l}\text { Patient satisfaction and comfort } \\
\text { Mastication }\end{array}$ & 4 weeks & $\begin{array}{c}\text { Both CGO and BBO improved the masticatory efficiency in } \\
\text { complete denture wearers }\end{array}$ \\
\hline Maxwell et al. [20] & Crossover clinical trial, 10 & Complete dentures & $\begin{array}{l}\mathrm{BBO} \\
\mathrm{CGO}\end{array}$ & $\begin{array}{l}\text { Electromyography of masseter } \\
\text { and anterior temporal muscles } \\
\text { Mastication }\end{array}$ & 4 weeks & $\begin{array}{l}\text { Masticatory ability is better when using canine-guided } \\
\text { dentures }\end{array}$ \\
\hline Elshoukouki et al. [6] & Crossover, 10 & Complete dentures & $\begin{array}{l}\text { CGO } \\
\mathrm{MO} \\
\mathrm{BBO}\end{array}$ & $\begin{array}{l}\text { Maxillary acrylic denture base } \\
\text { deformation was measured by } \\
\text { the strain gauge method } \\
\text { Mastication }\end{array}$ & 8 weeks & MO is recommended for debilitated alveolar ridges \\
\hline
\end{tabular}


Table 1. Cont.

\begin{tabular}{|c|c|c|c|c|c|c|}
\hline Study & Study Design and Participants & Prosthesis & Occlusion & Assessment Method & $\begin{array}{l}\text { Follow-Up } \\
\text { Period }\end{array}$ & Conclusions \\
\hline Abdelhamid et al. [21] & Crossover design, 12 & $\begin{array}{c}\text { Implant-retained lower } \\
\text { overdenture } \\
\text { and an upper conventional } \\
\text { complete denture }\end{array}$ & $\begin{array}{l}\text { CGO } \\
\text { BBO }\end{array}$ & Electromyography & 4 weeks & $\begin{array}{l}\text { CGO is similar to BBO in terms of masticatory muscle } \\
\text { activity }\end{array}$ \\
\hline Hofmann et al. [22] & & $\begin{array}{c}\text { Single maxillary complete } \\
\text { denture }\end{array}$ & $\begin{array}{l}\text { CGO } \\
\text { BBO }\end{array}$ & $\begin{array}{l}\text { Occlusal analysis } \\
\text { mastication }\end{array}$ & NM & $\begin{array}{l}\text { It appeared that canine-guided dentures led to considerable } \\
\text { dislocations during tooth-guided lateral movements, BBO } \\
\text { generated less disocclusion and denture movement }\end{array}$ \\
\hline Compagnoni et al. [23] & Randomized control trials, 15 & Complete denture & $\begin{array}{l}\text { CGO } \\
\text { BBO }\end{array}$ & Mastication & NM & $\begin{array}{l}\text { CGO-prescribed dentures report lateral disocclusion but no } \\
\text { functional impairment in patients }\end{array}$ \\
\hline Paleari et al. [25] & Randomized clinical trial, 44 & Complete dentures & $\begin{array}{l}\text { CGO } \\
\text { BBO }\end{array}$ & $\begin{array}{c}\text { Denture satisfaction } \\
\text { questionnaire and kinesiograph } \\
\text { instrument }\end{array}$ & 4 weeks & $\begin{array}{l}\text { Occlusal scheme alone has no effect on denture satisfaction } \\
\text { and kinesiographic analysis, except for the lower vertical } \\
\text { intrusion of the maxillary denture with CGO }\end{array}$ \\
\hline Rehmann et al. [26] & Clinical single-blind trial, 38 & Complete dentures & $\begin{array}{l}\text { CGO } \\
\text { BBO }\end{array}$ & $\begin{array}{l}\text { Patient satisfaction } \\
\text { and comfort }\end{array}$ & 2 weeks and 4 weeks & $\begin{array}{l}\text { Patients preferred } \mathrm{BBO} \text { in complete dentures when } \\
\text { compared with } \mathrm{CGO}\end{array}$ \\
\hline
\end{tabular}

OHRQoL: oral-health-related quality of life, CGO: canine-guided occlusion, BBO: bilateral balanced occlusion, MO: monoplane occlusion, LO: lingualized occlusion, NM: not mentioned. 
Table 2. Methodological quality assessment results of the included studies.

\begin{tabular}{|c|c|c|c|c|c|c|c|c|c|c|}
\hline \multirow{2}{*}{ Study } & \multirow{2}{*}{$\begin{array}{c}\text { Patient } \\
\text { Randomization }\end{array}$} & \multicolumn{2}{|c|}{ Blinding } & \multirow{2}{*}{$\begin{array}{l}\text { Withdrawal/Dropout } \\
\text { mentioned }\end{array}$} & \multirow{2}{*}{$\begin{array}{l}\text { Statistics } \\
\text { Applied }\end{array}$} & \multirow{2}{*}{ Sample Size } & \multirow{2}{*}{$\begin{array}{l}\text { Inclusion/Exclusion } \\
\text { Criteria Clear }\end{array}$} & \multirow{2}{*}{$\begin{array}{l}\text { Occlusal Performance } \\
\text { Measurement }\end{array}$} & \multirow{2}{*}{$\begin{array}{l}\text { Method of Error } \\
\text { Assessment }\end{array}$} & \multirow[b]{2}{*}{ Quality of Study } \\
\hline & & Participants' & Assessor & & & & & & & \\
\hline Pero et al. [9] & Yes & $\mathrm{UC}$ & No & Yes & Yes & Yes & Yes & Yes & Yes & Low \\
\hline Brandt et al. [10] & Yes & Yes & No & Yes & Yes & Yes & Yes & Yes & Yes & Low \\
\hline Schierz et al. [1] & Yes & Yes & No & Yes & Yes & Yes & Yes & Yes & Yes & Low \\
\hline Farias et al. [15] & Yes & Yes & Yes & Yes & Yes & Yes & Yes & Yes & Yes & Low \\
\hline Abdelhamid et al. [16] & No & No & No & No & Yes & Yes & Yes & Yes & Yes & $\mathrm{M}$ \\
\hline Heydecke et al. [7] & Yes & Yes & No & No & Yes & Yes & Yes & Yes & Yes & Low \\
\hline Afzal et al. [17] & Yes & No & No & No & Yes & Yes & Yes & Yes & Yes & Low \\
\hline Bolla et al. [18] & No & UC & No & No & Yes & Yes & Yes & Yes & UC & M \\
\hline Faten et al. [19] & Yes & UC & No & No & Yes & Yes & Yes & Yes & Yes & Low \\
\hline Maxwell et al. [20] & Yes & UC & No & Yes & Yes & Yes & Yes & Yes & Yes & Low \\
\hline Abdelhamid et al. [21] & No & No & No & No & Yes & Yes & Yes & Yes & Yes & M \\
\hline Hofmann et al. [22] & No & No & No & No & Yes & Yes & Yes & Yes & Yes & $\mathrm{M}$ \\
\hline Compagnoni et al. [23] & No & No & No & No & Yes & Yes & Yes & Yes & Yes & $\mathrm{M}$ \\
\hline Miralles et al. [24] & No & No & No & No & No & Yes & Yes & No & Yes & High \\
\hline Paleari et al. [25] & Yes & UC & No & Yes & Yes & Yes & Yes & Yes & Yes & Low \\
\hline Rehmann et al. [26] & Yes & Yes & No & UC & UC & Yes & No & UC & Yes & M \\
\hline
\end{tabular}

UC: unclear, M: moderate. 
Table 3. Newcastle-Ottawa quality assessment of the included studies.

\begin{tabular}{|c|c|c|c|c|}
\hline Author ID & Selection & Comparability & Exposure & Newcastle-Ottawa Quality (Total) \\
\hline Pero et al. [9] & $* * * *$ & * & $* *$ & Seven \\
\hline Brandt et al. [10] & $* * * *$ & * & $* * *$ & Eight \\
\hline Schierz et al. [1] & $* * *$ & * & $* *$ & Six \\
\hline Peroz et al. [14] & $* * *$ & * & ** & Six \\
\hline Farias et al. [15] & $* * * *$ & * & $* * *$ & Eight \\
\hline Abdelhamid et al. [16] & $* * *$ & * & $* *$ & Six \\
\hline Heydecke et al. [7] & $* * * *$ & * & $* * *$ & Eight \\
\hline Afzal et al. [17] & $* * *$ & * & $* * *$ & Seven \\
\hline Bolla et al. [18] & $* * *$ & * & $* *$ & Six \\
\hline Faten et al. [19] & $* * *$ & * & $* *$ & Six \\
\hline Maxwell et al. [20] & $* * *$ & * & $* * *$ & Seven \\
\hline Elshoukouki et al. [6] & $* * *$ & * & $* *$ & Six \\
\hline Abdelhamid et al. [21] & $* * *$ & * & $* *$ & Six \\
\hline Hofmann et al. [22] & $* * *$ & * & $* *$ & Six \\
\hline Compagnoni et al. [23] & $* * *$ & * & $* *$ & Six \\
\hline Miralles et al. [24] & $* * *$ & * & $* *$ & Six \\
\hline Paleari et al. [25] & $* * *$ & * & $* * *$ & Seven \\
\hline Rehmann et al. [26] & $* * *$ & * & $* * *$ & Seven \\
\hline
\end{tabular}

A study can be awarded a maximum of one star for each numbered item within the Selection and Exposure categories. A maximum of two stars can be given for Comparability. Each study can be awarded a total of 9 stars. A study was rated to have a low risk of bias if it received the maximum allowed number of 9 "stars" while moderate risk if it received 8,7 or 6 "stars" and high risk if it received 5 "stars" or less.

The analysis was based on three core quality parameters: case and group (selection, definition and representativeness), comparability (comparison of case and control groups, analysis and control of confounding variable) and exposure (outcome assessment), as well as the analysis of occlusal schemes in patients by different examiners, the evaluation of the study outcome related to different occlusal schemes clinically, the use of a universal assessment method for both control and case groups and a dropout rate of patients in the included studies. Each item scored 1 star if sufficiently reported, and each study scored from 1 to 8 stars.

\section{Results}

\subsection{Search Results}

In this review, there was a total of 1759 articles in the initial search. The articles were decreased to 930 irrelevant studies and then further decreased to 415 relevant studies and gradually to the final 18 articles $[1,6,7,9,10,14-26]$ after the application of the set exclusion and inclusion criteria. The total number of articles that included CGO was eighteen $[1,6,7,9,10,14-26]$, seventeen for BBO [1,6,9,10,14-26] and one each for LO [7] and MO [6]. The CGO scheme was compared in all 18 articles $[1,6,7,9,10,14-28]$ based on function, retention, satisfaction, muscle activity, esthetics and OHRQoL with BO, LO and MO. Thirteen full-text articles [5,29-35] were excluded, including the review articles, articles reporting natural occlusion or artificial occlusion without canine guidance and articles in which fixed prosthodontic restorations were used as a treatment option (Figure 1).

\subsection{Assessment of Various Occlusal Schemes from the Included Articles}

The function or mastication as a parameter of suitability with CGO was compared in $13(72.22 \%), 12 \mathrm{BBO}(66.66 \%), 1 \mathrm{LO}(5 \%)$ and $1 \mathrm{MO}(5.55 \%)$ articles. Esthetics with CGO was compared in $7(38.88 \%), 7 \mathrm{BBO}(38.88 \%), 0 \mathrm{LO}(0 \%)$ and $0 \mathrm{MO}(0 \%)$ articles. Retention with CGO was analyzed in $5(27.77 \%), 5 \mathrm{BBO}(27.77 \%), 0 \mathrm{LO}(0 \%)$ and $1 \mathrm{MO}(5 \%)$ articles. Muscle activity with CGO was compared in $5(27.77 \%), 5 \mathrm{BBO}(27.77 \%), 0 \mathrm{LO}(0 \%)$ and $0 \mathrm{MO}(0 \%)$ articles. OHRQoL with CGO was analyzed in $1(5.55 \%), 1 \mathrm{BBO}(5.55 \%), 0 \mathrm{LO}$ $(0 \%)$ and $0 \mathrm{MO}(0 \%)$ articles. Furthermore, phonetics with CGO was analyzed in $5(27.77 \%)$, 
$5 \mathrm{BBO}(27.77 \%), 0 \mathrm{LO}(0 \%)$ and $0 \mathrm{MO}(0 \%)$ articles. Patient satisfaction and comfort with CGO were compared in $5(27.77 \%), 5 \mathrm{BBO}(27.77 \%), 0 \mathrm{LO}(0 \%)$ and $0 \mathrm{MO}(0 \%)$ articles, as described in (Figure 2).

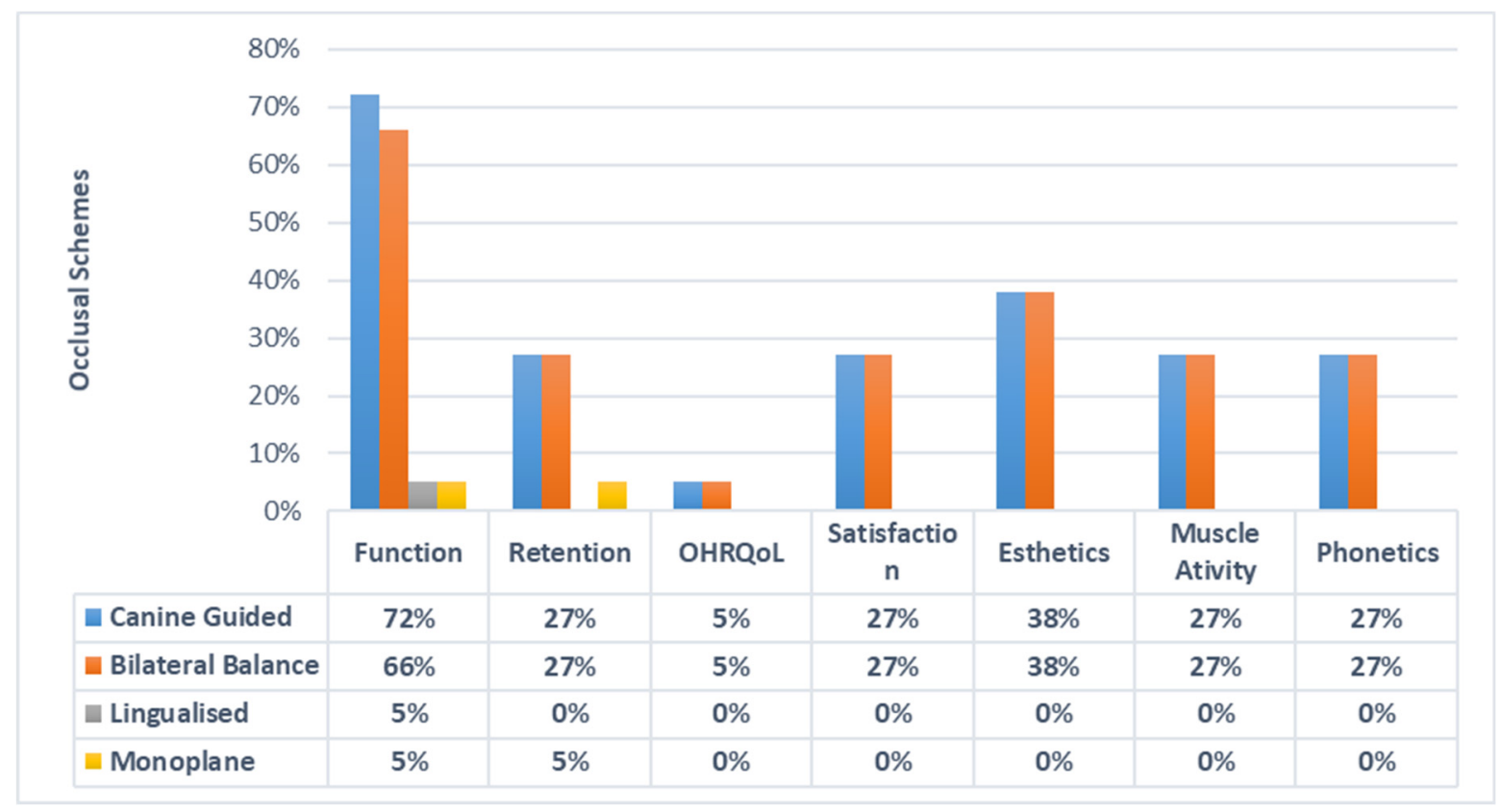

Figure 2. Assessment of different occlusal schemes with study outcomes.

Out of the 18 articles. The follow-up period up to 6 months was adopted in $16(88.88 \%)$ CGO studies, $15 \mathrm{BBO}(83.33 \%), 1 \mathrm{LO}(5.55 \%)$ and $1 \mathrm{MO}$ study (5.55\%), while only 1 , the article by Bola et al. [18], did a yearly follow-up. Removable complete dentures were used as a prosthesis to incorporate $16 \mathrm{CGO}(88.88 \%), 15 \mathrm{BBO}(83.33 \%), 1 \mathrm{LO}(5.55 \%)$ and $1 \mathrm{MO}$ $(5.55 \%)$, as described in Table 4. Maxillary and mandibular complete dentures were used as a prosthesis in 15 articles $[1,6,7,9,10,14,15,17-20,23-26]$, while a single complete maxillary denture was used in 1 article [22]. Moreover, implant-retained mandibular dentures as opposed to conventional maxillary dentures were used in two $(11.11 \%)$ articles $[16,21]$.

Table 4. Follow-up and type of prosthesis used over the different occlusal schemes.

\begin{tabular}{cccc}
\hline Occlusal Schemes & Follow-Up Period & Conventional Denture & Implant-Retained Denture \\
\hline Canine-guided occlusion & $88.88 \%$ & $88.88 \%$ & $11.11 \%$ \\
Bilateral balanced occlusion & $83.33 \%$ & $83.33 \%$ & $11.11 \%$ \\
Lingualized occlusion & $5.55 \%$ & $5.55 \%$ & $0 \%$ \\
Monoplane occlusion & $5.55 \%$ & $5.55 \%$ & $0 \%$ \\
\hline
\end{tabular}

\subsection{Results of Quality Assessment}

Out of the eighteen articles $[1,6,7,9,10,14-26]$ analyzed, blinding was performed in five articles $[1,7,10,15,26]$. In fourteen articles $[1,7,9,10,12-15,17,25,26]$, randomization was applied among the participants. The withdrawal/dropout rate was mentioned in six articles $[1,9,10,15,20,25]$. Suitable statistical tests were performed in three articles $[14,24,26]$. Subject criteria and sample size calculation were carried out in all the included articles $[1,6,7,9,10,14-26]$. Analysis of occlusal performance was performed in fifteen articles $[1,6,7,9,10,15-25]$. The method of error assessment was applied in 17 studies $[1,6,7,9,10,14-17,19-26]$. Moreover, eight articles were allocated a quality score of "medium" [6,14,16,18,21-23,26], and nine articles were labeled as "low" $[1,7,9,10,15,17,19,20,25]$. One article was assigned a quality score of "high" [24]. The results of the quality assessment are described in (Table 2). Additionally, the quality assess- 
ment of selected studies on NOS [13] ranged from six to eight points. A mean score of six was achieved for the included studies. All "eighteen" articles [1,6,7,9,10,14-26] included in this review fall in the "moderate" bias category (Table 3).

\subsection{General Outcomes of Included Studies}

The outcomes of the studies (stability, function, esthetics, retention, muscle activity, phonetics, patient satisfaction and OHRQoL) varied drastically when compared with occlusal schemes. The outcomes of the included studies showed superior suitability with CGO among the denture wearers. CGO emerged as the preferred occlusal scheme in a total of eight articles $[7,9,10,14,15,20,23,24]$, while four articles $[6,18,22,26]$ suggested that other occlusal schemes are better. Four articles $[1,16,19,21]$ predicted no difference between canine-guided occlusion and other occlusal schemes, while two articles $[17,18]$ concluded that occlusal schemes alone have a limited role in overall patient satisfaction (Figure 3).

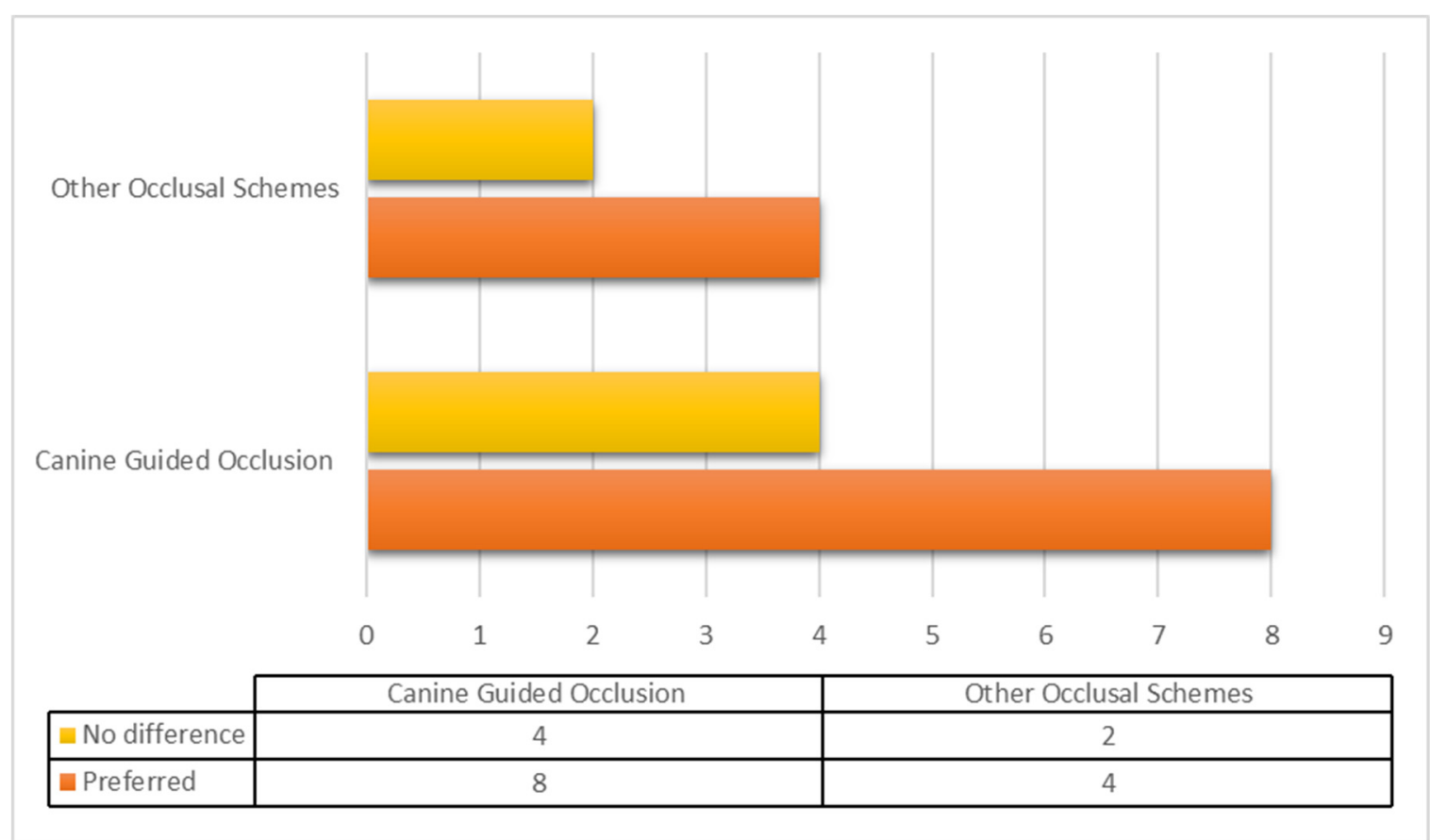

Figure 3. Distribution of suitable occlusal schemes from the included studies. Suitability of canine-guided occlusion versus other occlusal schemes (bilateral balanced occlusion, lingualized and monoplane occlusion) in terms of retention, stability, satisfaction, esthetics, oral-health-related quality of life and phonetics.

\section{Discussion}

The present systematic review compared various aspects of the canine-guided occlusion with other types of occlusal schemes in complete denture wearers. The selection of an adequate occlusal scheme in removable complete dentures is challenging $[27,36]$. Achieving all the objectives of complete denture making in edentulous patients involves the successful integration of patients' functional needs and psychological acceptance [37]. Different occlusal schemes for the removable prostheses have been proposed by various researchers over the years $[28,38]$. However, to date, there is no conclusive evidence to support which occlusal scheme is appropriate for the construction of a successful and functional complete denture [39]. Numerous studies have been carried out in the past, which have evaluated and compared occlusal concepts based on various parameters [40]. The current systematic review analyzed various aspects of canine-guided occlusion and other artificial occlusal schemes in removable complete dentures.

When forces act on the body in such a way that no motion results, there is stability, balance and equilibrium [41]. From prosthodontic aspects, this is the main goal while 
fabricating a complete denture, considering the forces that act on the denture teeth and the denture bases with their combined effect on the movement of the denture. A wellsupported, retentive and stable denture base is desired [42]. BBO is one of the earliest occlusion concepts advocated for the construction of complete dentures and involves the continuing contacts of as many maxillary and mandibular artificial teeth as possible at the centric relation and all eccentric mandibular movements [43]. Proponents of this scheme claim that dentures fabricated with BBO are more stable, with multiple point contacts in all excursive movements, particularly for edentulous patients with compromised ridges and neuromuscular skills [36,43]. In contrast, with CGO, the posterior teeth disengage during all excursive movements of the mandible, with the canine teeth making a vertical and horizontal overlap [14]. In centric occlusion, both types of schemes have simultaneous occlusal contacts; however, they differ in occlusal contacts during excursive/eccentric movements [44,45]. The selection of the optimal or appropriate occlusal scheme for edentulous patients has economical and clinical significance $[36,43,45]$. The construction of the occlusal scheme with $\mathrm{BBO}$ is more complex and time-consuming compared to the canine-guided scheme [1]. It is logical to use technical procedures that produce comparable and acceptable clinical results with minimum time and effort, rather than opting for more complicated occlusal schemes such as BBO. Although BBO has been considered successful and functional for complete dentures for many years, the scientific evidence to support it is still inconclusive [15].

According to the present review, CGO is another reliable occlusal scheme for the arrangement of complete denture teeth compared to the relevant published artificial occlusal schemes. The articles searched in this review quote that CGO is the most preferable over other occlusal schemes because of its simplicity and ease of fabrication [46]. However, it must be emphasized that the construction of a satisfactory complete set of dentures depends on technical, biological and physiological interactions between the patient and dentist [47]. Besides the clinical skills of the dentist and technician, the factors associated with the patients are also critical and equally important for optimum function and satisfaction with complete dentures [48]. Various factors, such as adhesion/cohesion, saliva viscosity/flow, shape, quality, quantity and resorption of alveolar ridges, the skeletal relationship of the upper and lower arches, condition of the oral mucosa, vestibular depth, neuromuscular coordination of the patient and tongue hypertrophy, play a vital role on the outcome of the complete denture treatment $[48,49]$.

The current research states that CGO is a reliable occlusal scheme for the arrangement of denture teeth. BBO, $\mathrm{LO}$ and $\mathrm{MO}$ may be used directly to establish occlusal schemes consistent with previous studies [2,6]. This was an unexpected finding as it contradicts the widely held belief that artificial occlusion in denture teeth is ideal with BBO for denture function and stability. In our study, there was a significant difference between different occlusal schemes in terms of stability, function, muscle activity, esthetics, retention and OHRQoL suggesting that patient satisfaction varies in relation to various occlusal schemes. Meanwhile, the CGO occlusal scheme was different in function only when compared with $\mathrm{BBO}$; however, the latter is not preferred due to the complexity of construction and time-consuming adjustments visits. Comparing the results of all occlusal schemes, BBO, $\mathrm{LO}, \mathrm{MO}$ did not seem to be suitable methods for denture occlusion. In contrast, the studies carried out by Rehmann et al. [26] and Elshoukouki et al. [6] still favor BBO and MO in denture wearers.

Anterior teeth group function or the canine-guided occlusal scheme have been reported for superior functional efficiency for chewing/mastication. According to the literature review, differences between the various occlusal schemes were observed in terms of patient satisfaction in relation to various factors such as stability, function, muscle activity, esthetics, retention and OHRQoL [50]. In the current review, CGO was preferred in comparison to other artificial occlusal schemes in terms of function and stability, as reported by several researchers $[9,14,18]$. Some researchers have named these "lateral occlusal guidance studies," where canine- and premolar-guided occlusion are preferred over BBO [51]. CGO 
was preferred for esthetics, phonetics, masticatory function and retention in a crossover study with 50 subjects (10 dropouts), where all subjects preferred CGO, but a greater adjustment time was involved [52-54]. Another important point and advantage of the CGO scheme in complete denture wearers could be its ease of modification by the alteration of canines [15]. For patients with compromised ridges, poor neuromuscular coordination and a reduced ability for adaptation to $\mathrm{CGO}$, with little modification, the occlusal scheme can be changed to BBO $[15,55]$. Nevertheless, it is worth attempting to establish CGO first over $\mathrm{BBO}$ because of its superior functional performance.

The present review had some limitations such as the heterogeneity of the included studies present in all the occlusal schemes. The inclusion and exclusion criteria of the patients, as well as the scale established for the measurement/classification of patient satisfaction, varied, which may have affected the results of the studies. Most of the values reported were based on the patients' individual responses. Therefore, the results could be interpreted with caution, and a direct extrapolation of this review to the clinical performance of various occlusal schemes should be carefully made. The authors suggest additional randomized controlled clinical trial studies for various complete denture occlusal schemes should be carried out to explore their effects on denture retention and the transfer of occlusal stresses. The influence of local factors should be considered, such as mucosal resiliency, residual ridge quality and quantity, salivary parameters, skeletal ridge relationships and general factors such as patient age, systemic health, parafunctional activities and psychological factors, on occlusal concept choice. This study will help future clinicians in restoring teeth with satisfactory occlusion. A suitable occlusal scheme would be a critical factor for the fabrication of a successful complete denture. However, there is no conclusive evidence to support which occlusal design is more appropriate for fabricating a successful complete denture.

\section{Conclusions}

The type of occlusal scheme influences the complete denture patients' masticatory efficiency, satisfaction, retention, phonetics, and esthetics. All schemes, if wisely used, can bring out good clinical results. Nevertheless, physical, physiological, mechanical and psychological factors play a vital role in the success of complete dentures. A canineguided occlusal scheme is preferred because of its simplicity, less time consumption, good masticatory performance, ease of fabrication and modification into bilateral balanced occlusion if required. Further studies are required to reduce the controversies related to jaw relation, gnathology and occlusal schemes in complete dentures.

Author Contributions: Conceptualization: N.A., M.A.H. and M.S.A.; methodology, N.A. and M.A.H.; software: N.A., M.S.A. and N.B.J.; validation, M.S.Z., N.A. and S.R.H.; formal analysis: N.A., N.B.J. and M.A.H.; investigation: M.S.Z. and N.A.; resources, M.S.Z. and S.R.H.; data curation, N.A. and M.A.H.; writing—original draft preparation: N.A., M.S.Z., S.R.H. and M.A.H.; writing—review and editing: S.R.H., N.A. and M.S.Z.; visualization: N.B.J. and M.S.A.; supervision: N.A., M.S.Z. and S.R.H.; project administration: N.A. and M.S.Z. All authors have read and agreed to the published version of the manuscript.

Funding: This research received no external funding.

Institutional Review Board Statement: Not applicable.

Informed Consent Statement: Not applicable.

Data Availability Statement: Data supporting the reported results can be found at PubMed (https: / / pubmed.ncbi.nlm.nih.gov, accessed on 11 March 2021), Cochrane Collaboration (https: / / www. cochranelibrary.com, accessed on 11 March 2021), Scopus (https:/ / www.scopus.com, accessed on 11 March 2021), ScienceDirect (https:/ / www.sciencedirect.com, accessed on 11 March 2021) and Europe PMC (https:/ / www.europepmc.org, accessed on 11 March 2021).

Conflicts of Interest: The authors declare no conflict of interest. 


\section{References}

1. Schierz, O.; Reissmann, D. Influence of guidance concept in complete dentures on oral health related quality of life-Canine guidance vs. bilateral balanced occlusion. J. Prosthodont. Res. 2016, 60, 315-320. [CrossRef]

2. Bilhan, H.; Geckili, O.; Ergin, S.; Erdogan, O.; Ates, G. Evaluation of satisfaction and complications in patients with existing complete dentures. J. Oral Sci. 2013, 55, 29-37. [CrossRef]

3. Shamsolketabi, S.; Nili, M. The effect of denture adhesive on the efficiency of complete denture in patients with different alveolar ridges. Dent. Res. J. 2018, 15, 271-275.

4. Zhao, K.; Mai, Q.; Wang, X.; Yang, W.; Zhao, L. Occlusal designs on masticatory ability and patient satisfaction with complete denture: A systematic review. J. Dent. 2013, 41, 1036-1042. [CrossRef]

5. Maddula, R.T.; Ariga, P.; Jain, A.R. Systematic review of masticatory efficiency with different occlusal scheme in conventional complete dentures. Drug Invent. Today 2018, 10, 1626-1631.

6. El-Shoukouki, A.H.; Fuad, M.M. Maxillary Acrylic Denture Base Deformation as Related To Different Occlusal Concepts for Complete Denture. Egypt. Dent. J. 2007, 53, 1.

7. Heydecke, G.; Akkad, A.S.; Wolkewitz, M.; Vogeler, M.; Türp, J.C.; Strub, J.R. Patient ratings of chewing ability from a randomised crossover trial: Lingualised vs. first premolar/canine-guided occlusion for complete dentures. Gerodontology 2007, 24, 77-86. [CrossRef] [PubMed]

8. Carlsson, G.; Omar, R. The future of complete dentures in oral rehabilitation. A critical review. J. Oral Rehabil. 2010, 37, 143-156. [CrossRef] [PubMed]

9. Pero, A.C.; Scavassin, P.M.; Policastro, V.B.; de Oliveira Júnior, N.M.; Marin, D.O.M.; da Silva, M.D.D.; Cassiano, A.F.B.; de Sousa Santana, T.; Compagnoni, M.A. Masticatory function in complete denture wearers varying degree of mandibular bone resorption and occlusion concept: Canine-guided occlusion versus bilateral balanced occlusion in a cross-over trial. J. Prosthodont. Res. 2019, 63, 421-427. [CrossRef]

10. Brandt, S.; Danielczak, R.; Kunzmann, A.; Lauer, H.; Molzberger, M. Prospective clinical study of bilateral balanced occlusion (BBO) versus canine-guided occlusion (CGO) in complete denture wearers. Clin. Oral Investig. 2019, 23, 4181-4188. [CrossRef]

11. Moher, D.; Liberati, A.; Tetzlaff, J.; Altman, D.G. Preferred reporting items for systematic reviews and meta-analyses: The PRISMA statement. Ann. Intern. Med. 2009, 151, 264-269. [CrossRef]

12. Higgins, J.P.; Thomas, J.; Chandler, J.; Cumpston, M.; Li, T.; Page, M.J.; Welch, V.A. Cochrane Handbook for Systematic Reviews of Interventions; John Wiley \& Sons: Hoboken, NJ, USA, 2019.

13. Wells, G.A.; Shea, B.; O'Connell, D. The Newcastle-Ottawa Scale (NOS) for Assessing the Quality of Nonrandomised Studies in Meta-analyses; Ottawa Hospital Research Institute: Ottawa, ON, Canada, 2011.

14. Peroz, I.; Leuenberg, A.; Haustein, I.; Lange, K. Comparison between balanced occlusion and canine guidance in complete denture wearers-A clinical, randomized trial. Quintessence Int. 2003, 34, 607-612. [PubMed]

15. Farias Neto, A.; Mestriner Junior, W.; da Fonte Porto Carreiro, A. Masticatory efficiency in denture wearers with bilateral balanced occlusion and canine guidance. Braz. Dent. J. 2010, 21, 165-169. [CrossRef]

16. Abdelhamid, A.M.; Hanno, K.I.; Imam, M.H. A prospective cross-over study to evaluate the effect of two different occlusal concepts on the masseter muscle activity in implant-retained mandibular overdentures. Int. J. Implant Dent. 2015, 1, 1-8. [CrossRef]

17. Afzal, M.; Majeed, M.I.; Mirza, B.A.Q. Assessment of patient satisfaction and Masticatory efficiency with balanced occlusion compared to canine Guided occlusion in complete denture wearers. Pak. Oral Dent. J. 2017, 37, 504-509.

18. Bolla, V.L.; Bondugula, V.; Munnangi, S.R.; Tandu, A. Comparison of patient satisfaction in complete denture patients with different occlusal schemes. Int. J. Appl. Dent. Sci. 2017, 3, 51-52.

19. Faten, S.A.; Nazik, A.E.; Esraa, M.A. Colorimetric comparative analysis of masticatory efficiency in complete denture wearers with two different occlusal concepts. Alex. Dent. J. 2016, 41, 117-121. [CrossRef]

20. Maxwell, D.; Odang, R.; Koesmaningati, H. Correlation of Masticatory Muscle Activity with Masticatory Ability in Complete Denture Patients with Canine Guidance and Balanced Occlusion. J. Phys. Conf. Ser. 2017, 884, 1-7. [CrossRef]

21. Abdelhamid, A.M.; Hanno, K.I.H.; Imam, M.H. The effect of two different occlusal concepts on the masseter muscle activity in implant retained mandibular overdentures. J. Dent. Implants 2017, 7, 20.

22. Hofmann, M.; Knauer, G. Studies on canine guidance in complete dentures. Dtsch. Zahnarztl. Z. 1990, 45, 566-570. [PubMed]

23. Compagnoni, M.A.; Leles, C.R.; Barbosa, D.B.; Valverde, G.B. Oclusão em dentaduras completas: Estudo comparativo entre oclusão balanceada bilateral e desoclusão pelo canino. Rev. CROMG 2002, 8, 92-97.

24. Miralles, R.; Bull, R.; Manns, A.; Roman, E. Influence of balanced occlusion and canine guidance on electromyographic activity of elevator muscles in complete denture wearers. J. Prosthet. Dent. 1989, 61, 494-498. [CrossRef]

25. Paleari, A.; Marra, J.; Rodriguez, L.; De Souza, R.; Pero, A.C.; De Assis Mollo Júnior, F., Jr.; Compagnoni, M.A. A cross-over randomised clinical trial of eccentric occlusion in complete dentures. J. Oral Rehabil. 2012, 39, 615-622. [CrossRef] [PubMed]

26. Rehmann, P.; Balkenhol, M.; Ferger, P.; Wöstmann, B. Influence of the occlusal concept of complete dentures on patient satisfaction in the initial phase after fitting: Bilateral balanced occlusion vs canine guidance. Int. J. Prosthodont. 2008, 21, 1.

27. Motwani, B.; Sidhaye, A. The need of eccentric balance during mastication. J. Prosthet. Dent. 1990, 64, 689-690. [CrossRef]

28. Trapozzano, V.R. Tests of balanced and nonbalanced occlusions. J. Prosthet. Dent. 1960, 10, 476-487. [CrossRef] 
29. Jaafar Abduo, B.; DclinDent, M. Occlusal schemes for complete dentures: A systematic review. Int. J. Prosthodont. 2013, 26, 26-33. [CrossRef]

30. Akören, A.; Karaačaçliočlu, L. Comparison of the electromyographic activity of individuals with canine guidance and group function occlusion. J. Oral Rehabil. 1995, 22, 73-77. [CrossRef]

31. Ximinis, E.; Tortopidis, D. Electromyographic activity changes of jaw-closing muscles in patients with different occlusion schemes after fixed prosthetic restoration. Balk. J. Dent. Med. 2018, 22, 157-162. [CrossRef]

32. Michielin, M.; Daniani, M.G.; Orthlieb, J.D.; Simon, J. Statistical analysis of functional interrelations between anterior guidance and posterior determinants. Cah. Prothese 1990, 70, 52-65.

33. Abduo, J.; Tennant, M.; Mcgeachie, J. Lateral occlusion schemes in natural and minimally restored permanent dentition: A systematic review. J. Oral Rehabil. 2013, 40, 788-802. [CrossRef]

34. Jemt, T.; Lundquist, S.; Hedegard, B. Group function or canine protection. J. Prosthet. Dent. 2004, 91, 403-408. [CrossRef]

35. Thalji, G.; McGraw, K.; Cooper, L.F. Maxillary Complete Denture Outcomes: A Systematic Review of Patient-Based Outcomes. Int. J. Oral Maxillofac. Implants 2016, 31, 169-181. [CrossRef]

36. Sabir, S.; Regragui, A.; Merzouk, N. Maintaining occlusal stability by selecting the most appropriate occlusal scheme in complete removable prosthesis. Jpn. Dent. Sci. Rev. 2019, 55, 145-150. [CrossRef] [PubMed]

37. Marchini, L. Patients' satisfaction with complete dentures: An update. Braz. Dent. Sci. 2014, 17, 5-16. [CrossRef]

38. Aarts, J.M.; Payne, A.G.; Thomson, W.M. Patients' evaluation of two occlusal schemes for implant overdentures. Clin. Implant Dent. Relat. Res. 2008, 10, 140-156. [CrossRef] [PubMed]

39. Palla, S. Occlusal considerations in complete dentures. In Science and Practice of Occlusion; Quintessence: Batavia, IL, USA, 1997.

40. Rangarajan, V.; Yogesh, P.B.; Gajapathi, B.; Ibrahim, M.M.; Kumar, R.G.; Karthik, M. Concepts of occlusion in prosthodontics: A literature review, part II. J. Indian Prosthodont. Soc. 2016, 16, 8-14.

41. Imran, T.; Ahmed, N.; Nazeer, B. Pattern of occlusal contacts in intercuspal position of natural teeth. Int. J. Dent. Res. 2016, 4, 19-21. [CrossRef]

42. Jain, P.; Rathee, M. Stability in Mandibular Denture; StatPearls Publishing LLC: Treasure Island, FL, USA, 2020.

43. Lemos, C.; Verri, F.; Gomes, J.; Santiago Júnior, J.; Moraes, S.; Pellizzer, E. Bilateral balanced occlusion compared to other occlusal schemes in complete dentures: A systematic review. J. Oral Rehabil. 2018, 45, 344-354. [CrossRef] [PubMed]

44. Abduo, J.; Bennamoun, M.; Tennant, M.; McGeachie, J. Effect of prosthodontic planning on lateral occlusion scheme: A comparison between conventional and digital planning. J. Appl. Oral Sci. 2015, 23, 196-205. [CrossRef] [PubMed]

45. Iegami, C.M.; de Melo Lopes, D.; Nakamae, A.E.M.; Uehara, P.N.; Tamaki, R. Different occlusal schemes in a persistent protruding complete denture wearer. Case Rep. Dent. 2016, 2016, 7418686. [CrossRef]

46. Bhambhani, R.; Joshi, S.; Roy, S.S.; Shinghvi, A. Choosing the denture occlusion-A Systematic review. J. Indian Prosthodont. Soc. 2020, 20, 269. [PubMed]

47. Berg, E. Acceptance of full dentures. Int. Dent. J. 1993, 43, 299-306. [PubMed]

48. Čelebić, A.; Knezović-Zlatarić, D.; Papić, M.; Carek, V.; Baučić, I.; Stipetić, J. Factors related to patient satisfaction with complete denture therapy. J. Gerontol. Ser. A Biol. Sci. Med. Sci. 2003, 58, M948-M953. [CrossRef]

49. Habib, S.R.; Azad, A.A. Comparison of patient's satisfaction with replacement complete dentures fabricated by copy denture technique versus conventional technique. J. Pak. Dent. Assoc. 2009, 18, 9-13.

50. Tarazi, E.; Ticotsky-Zadok, N. Occlusal schemes of complete dentures-A review of the literature. Refuat Hapeh Vehashinayim 2007, 24, 56-64.

51. Brewer, A.A.; Reibel, P.R.; Nassif, N.J. Comparison of zero degree teeth and anatomic teeth on complete dentures. J. Prosthet. Dent. 1967, 17, 28-35. [CrossRef]

52. Clough, H.E.; Knodle, J.M.; Leeper, S.H.; Pudwill, M.L.; Taylor, D.T. A comparison of lingualized occlusion and monoplane occlusion in complete dentures. J. Prosthet. Dent. 1983, 50, 176-179. [CrossRef]

53. Kawai, Y.; Ikeguchi, N.; Suzuki, A.; Kuwashima, A.; Sakamoto, R.; Matsumaru, Y.; Kimoto, S.; Iijima, M.; Feine, J.S. A double blind randomized clinical trial comparing lingualized and fully bilateral balanced posterior occlusion for conventional complete dentures. J. Prosthodont. Res. 2017, 61, 113-122. [CrossRef] [PubMed]

54. Madalli, P.; Murali, C.; Subhas, S.; Garg, S.; Shahi, P.; Parasher, P. Effect of occlusal scheme on the pressure distribution of complete denture supporting tissues: An in vitro study. J. Int. Oral Health JIOH 2015, 7, 68. [PubMed]

55. Sutton, A.; McCord, J. A randomized clinical trial comparing anatomic, lingualized, and zero-degree posterior occlusal forms for complete dentures. J. Prosthet. Dent. 2007, 97, 292-298. [CrossRef] [PubMed] 